Бухтаярова Е.Ю.

Высшая школа психологии, педагогики и физической культуры ФГАОУ ВО «Северный (Арктический) фредеральный университет имени М.В. Ломоносова»,

Архангельск, Российская Федерация.

iD ORCID: https://orcid.org/0000-0001-8776-3147, e-mail: bulena17@yandex.ru

Резюме: Автор статьи уделяет особое внимание тому, что поиск новых направлений совершенствования коррекционно-логопедической работы с детьми с тяжёлыми нарушениями речи непосредственно связан с изменением требований к содержанию дошкольного образования. В отечественной логопедии на сегодняшний день наиболее приоритетной и особенно полно разработанной является коррекционная работа, направленная на преодоление возникающих или уже имеющихся нарушений звукопроизношения, фонематического слуха и грамматического строя речи. Цель исследования - теоретическое обоснование проблемы исследования и разработка серии логопедических занятий с использованием наглядного моделирования при обучении старших дошкольников с тяжёлыми нарушениями речи составлению творческих рассказов. В ходе исследования применялись следующие методы исследования: изучение литературы по вопросу исследования; эксперимент - констатирующий, формирующий, контрольный; методы математической статистики; качественный и количественный метод обработки результатов эксперимента; наблюдение. Делается вывод о том, что создание мотивации общения, связанной с творческой деятельностью, наглядной ситуацией, ставит ребёнка в такие условия, когда у него возникает самостоятельное желание высказаться, поделиться своими впечатлениями. Формирование навыков творческого рассказывания у детей старшего дошкольного возраста, имеющих тяжёлые нарушения речи, представляет большие трудности. Творческое рассказывание является одним из эффеективных средств развития речи. Приём наглядного моделирования может быть использован в работе над всеми видами связного высказывания, в частности это относится к творческому рассказыванию. В ходе использования приёма наглядного моделирования дети знакомятся с графическим способом представления информации: контурные изображения предметов с наименьшим количеством деталей, символические изображения предметов, планы и условные обозначения, используемые в них.

Ключевые слова: диалог, связная речь, монолог, тяжёлые нарушения речи, творческое рассказывание, наглядное моделирование.

Для цитирования: Бухтаярова Е.Ю. Наглядное моделирование как средство обучения старших дошкольников с тяжёлыми нарушениями речи составлению творческих рассказов // Развитие образования. - 2020. - № 1 (7). C. $35-40$. DOI:10.31483/r-74615.

\title{
Visual Modeling as a Means of Teaching Creative Storytelling to Senior Preschoolers with Severe Speech Impairments
}

Elena Y. Bukhtayarova

Higher School of Psychology, Pedagogy and Physical Culture of FBEI of HE "M.V. Lomonosov Northern (Arctic) Federal University", Arkhangelsk, Russian Federation.

(D)ORCID: https://orcid.org/0000-0001-8776-3147, e-mail: bulena17@yandex.ru

\begin{abstract}
The article is specifically concerned with the fact that the search for new ways of improving corrective logopedic work with children diagnosed with severe speech disorders is directly associated with changes in the requirements concerning the content of preschool education. Today, the corrective work aimed at addressing emerging or existing impairments of speech and its grammatical structure, as well as phonemic hearing is prioritized in the Russian logopedics, being the most well-developed. The aim of this study is to establish the theoretical basis for the research problem and to develop a course of logopedic classes using visual modeling for developing creative storytelling skills in senior preschoolers with severe speech impairments. The following methods have been used in the study: analysis of literature on the research subject, experiments, methods used in mathematical statistics, qualitative and quantitative methods of processing the experimental findings, observation. It can be concluded that creating motivating communication associated with creative activity or a visual situation creates conditions for children's independent will to speak out and share their opinion. Developing creative storytelling skills in children of senior preschool age with severe speech disorders presents great difficulties. Creative storytelling is an effective means of speech development. The method of visual simulation can be used when working on all types of coherent expression, in particular, this applies to creative storytelling. In the course of visual modeling children will become familiar with graphic ways of presenting information: images of outlined objects with a minimal amount of details, symbolic images of objects, plans and symbols used in them.
\end{abstract}

Keywords: coherent speech, dialogue, monologue, severe speech disorders, creative storytelling, visual modeling.

For citation: Elena Y. Bukhtayarova (2020). Visual Modeling as a Means of Teaching Creative Storytelling to Senior Preschoolers with Severe Speech Impairments. Razvitie obrazovaniya = Development of education, 1(7), 35-40. (In Russ.) DOI:10.31483/r-74615. 


\section{Шкул умӗнхи аслӑ ушкӑнӑн пуплевре пысӑк кӑлтӑк пур ачисене кӑтартуллӑ моделированипе усӑ курса пултарулӑх калавӗсем хайлама вӗрентесси}

\section{Бухтаярова Е.Ю.}

АВ ФПА «М.В. Ломоносов ячӗллӗ С̧урс̧ӗр (Арктика) фредераци университечӗ» ВУн Психологи

педагогика тата ӱт-пӳ культури аслӑ шкулӗ,

Архангельск, Рас̧с̧ей Патшалӑхе̌.

(D) ORCID: https://orcid.org/0000-0001-8776-3147, e-mail: bulena17@yandex.ru

Аннотаци: Статья авторӗ ятарласа палӑртнӑ тӑрӑх, пуплевре пысӑк кӑлтӑк пур ачасемпе тӑвакан коррекципе логопеди е̌с̧не лайӑхлатма кирлӗ суллйӗр шыравӗ шкул умӗнхи вӗренӳ умне тухса тӑнӑ пысӑк требованисенчен тухса тӑрать. Тӑван с̧ӗр-шыв логопедийӗнче, паян кун, пӗлтерӗшӗпе чи палли те тӗпчени тарӑнни енчен коррекци ӗс̧ӗ палӑрса тӑрать. Вӑл сасӑ кӑларассинче, фронема туяссинче, грамматикӑна ӑнкарассинче пулма пултаракан е халь тӗл пулакан йывӑрлӑхсене пӗтерессипе с̧ыхӑннӑ. Тӗпчевӗн тӗллевӗ - тӗпчев ыйтӑвне теори енчен никӗслесси тата шкул умӗнхи аслӑ ушкӑнӑн пуплевре пысӑк кӑлтӑк пур ачисене кӑтартуллӑ моделировани мелӗпе усӑ курса пултарулӑх калавӗсем хайлама вӗрентнӗ чухне кирлӗ логопеди занятийӗсен серине хатӗрлесси. Тӗпчев вӑхӑтӗнче с̧ак меслетсемпе усӑ курнӑ: тӗпчев темипе с̧ырнӑ литературӑна тишкерни, эксперимент (констатаци тӑваканни, йӗркелекенни, тӗрӗслекенни); математика статистикин меслече̌сем; эксперимент пӗтӗмлетӗвӗсене пахалӑх тата шутлав меслечӗпе хатӗрлени, сӑнав. Пӗтӗмлетӳре каланӑ тӑрӑх, хутшӑнӑва кӗрес кӑмӑла пултарулӑх ӗс̧ӗн туртӑмӗпе, кӑтартуллӑ лару тӑрӑвӑн витӗмӗпе суӗклени ачана шухӑша хӑй тӗллӗн пӗлтерес, мӗн курни-илтнине, туйнине хыпарлас ӗмӗтне вӑратать. Аслӑ ушкӑнӑн пуплевре пысӑк кӑлтӑк пур ачисене кӑтартуллӑ моделировани мелӗпе усӑ курса пултарулӑх калавӗсем хайлама вӗрентнӗ чухне йывӑрлӑх пайтах тӗл пулать. Пултарулӑха вӑй парса калав тутарни пуплеве аталантармалли чи тухӑс̧лӑ мелсенчен пӗри пулса тӑрать. Кӑтартуллӑ моделированипе сыххӑнуллӑ калавӑн мӗн пур тӗсне (тӗслӗхрен, творчествӑллӑ каласа пама) ве̌рентме юрать. Кӑтартуллӑ моделированипе усӑ курнӑ чухне ачасем инфрормацие пӗлтерме юрӑхлӑ графика мелӗпе паллашас̧с̧ӗ: сахал пайран тӑракан япалан ӗмелкине (контурне) ӱкерес̧сеӗ, япаласен символӗпе усӑ курас̧с̧ӗ, хут с̧ине плансене, вӗсенче усӑ куракан паллӑсене кус̧арас̧с̧ӗ.

Tӗп сӑмахсем: пуплевӗн пысӑк кӑлтӑкӗ, с̧ыхӑнуллӑ пуплев, пултарулӑх калавӗ, кӑтартуллӑ моделировани, диалог, монолог.

Цитатӑлама: Бухтаярова Е.Ю. Шкул умӗнхи аслӑ ушкӑнӑн пуплевре пысӑк кӑлтӑк пур ачисене кӑтартуллӑ моделированипе усӑ курса пултарулӑх калавӗсем хайлама вӗрентесси // Вӗренў аталанӑвӗ. - 2020. - № 1 (7). С. $35-40$. DOI:10.31483/r-74615.

\section{Введение}

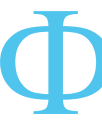
едеральный государственный образовательный стандарт дошкольного образования формулирует целевые ориентиры: развитие интереса и мотивации детей к познанию мира и творчеству. Задача развития речевого творчества формирование позиции активного участника в речевом взаимодействии $[1$, с. 7, с. 28$]$.

Потребность в коммуникации - это первое условие речевого развития ребёнка. Развитие речи имеет определяющую роль в регуляции поведения и деятельности на всех этапах развития ребёнка. Ребёнок овладевает речью в общении с взрослым. Первая функция речи - это высказывание, сообщение и понимание, то есть коммуникация. Общение требует соответствующей системы средств, которая позволяет передать свои мысли и переживания, и понять своего собеседника. Но даже самое примитивное речевое общение уже содержит в себе обобщение, а значит, связано с развитием сознания и мышления ребёнка. Следовательно, своевременное и правильное овладение речью имеет чрезвычайное значение для общего развития ребёнка. Проблема задержки речевого развития у детей, то есть несвоевременное развитие средств общения, является тем фактором, который затрудняет полноценное общение, что, в свою очередь, может влиять на весь процесс формирования личности ребёнка.

Основная часть. Изучив реестр Программ дошкольного образования, представленных на сайте Федерального института развития образования и допущенных к внедрению, можно сделать вывод, что все программы предусматривают задачу развития речевого творчества детей старшего дошкольного возраста и на этой основе формирование устойчивой потребности в речевой творчестве как виде деятельности [9].

Задачи развития речевого детского творчества в игре, театрализации, совместной деятельности и общении определены, но технологии развития этого речевого творчества не разработаны. Аудитория детей старшего дошкольного возраста слишком разнообразна по уровню сформированности представлений об окружающем мире, речевых и интеллектуальных возможностей. Не все дети без специального обучения способны овладеть творческим рассказыванием.

«... детское литературное творчество, как игра, в основе своей не порвало ещё связи с личной заинтересованностью и личным переживанием ребёнка. Смысл и значение этого творчества только в том, что оно позволяет ребёнку проделать тот крутой перевал в развитии творческого воображения, который даёт новое и остающееся на всю жизнь направление его фантазии» [2, с. 55].

Работы, рассматривающие вопросы освоения детьми родного языка, речевой деятельности, развитие на этой базе творческих возможностей ребёнка, поиск новых методов и приёмов обучения их связной речи, приобретают особую актуальность. Одним из эффективных средств развития связной речи является творческое рассказывание. Творческий рассказ - это рассказ, придуманный самим ребёнком, обязательным компонентом которого должны быть самостоятельно созданные ребёнком новые образы, действия, ситуации. «Новые»это образы, частично встречающиеся в реальной жизни и «достроенные» в воображении $[4 ; 5]$. 
Одним из способов облегчения планирования связного высказывания служит наглядное моделирование. Использование разного вида наглядности (картины, картинки, иллюстрации, схемы и пр.) позволяет дошкольникам более полно усваивать словесный материал, надолго удерживая его в памяти. Приём наглядного моделирования может быть использован в работе над всеми видами связного высказывания, в частности это относится к творческому рассказыванию.

В ходе использования приёма наглядного моделирования дети знакомятся с графическим способом представления информации: контурные изображения предметов с наименьшим количеством деталей, символические изображения предметов, планы и условные обозначения, используемые в них. План, как наглядная модель, способствует организации процесса творческого рассказывания. Следует отметить, что методические источники не определяют чёткой последовательности работы по обучению детей наглядному моделированию применительно к развитию связной речи.

Все вышеперечисленные аргументы свидетельствуют об актуальности выбранной нами темы исследования и позволяют сформулировать проблему исследования: каковы условия наглядного моделирования при обучении старших дошкольников с тяжёлыми нарушениями речи составлению творческих рассказов?

Цель исследования: теоретическое обоснование проблемы исследования и разработка серии логопедических занятий с использованием наглядного моделирования при обучении старших дошкольников с тяжёлыми нарушениями речи составлению творческих рассказов.

Можно предположить, что обучение детей старшего дошкольного возраста с тяжёлыми нарушениями речи составлению творческих рассказов может быть более эффективным, если использовать наглядное моделирование в логопедических занятиях при следующих условиях:

1) использования плана-схемы для облегчения логики построения связного высказывания;

2) кодирования информации в наглядных моделях для облегчения запоминания слов всеми детьми;

3) вариативности выбора слов-моделей для последующего творческого рассказа;

4) участия всех детей в процессе создания наглядных моделей;

5) записи текста в ходе составления творческого рассказа для последующего анализа речевой деятельности детей;

6) изготовления миникнижек для демонстрации результата совместного труда.

Методы исследования: изучение литературы по вопросу исследования; эксперимент - констатирующий, формирующий, контрольный; методы математической статистики; качественный и количественный метод обработки результатов эксперимента; наблюдение.

Творческое рассказывание - это один из видов детского сочинительства. Понятие «творческий рассказ» - условное название рассказа, который ребёнок придумывает сам, можно предположить, что элемент творчества есть в любом детском рассказе [6].

Творческий рассказ - это более высокая ступень развития связной речи, так как ребёнок должен обла- дать достаточным запасом знаний и представлений об окружающем мире, словарным запасом, уметь строить логические грамматические конструкции и облекать всё это в сюжет [8].

По мнению лингвистов, должны существовать определённые требования к рассказыванию детей:

1. Самостоятельность. Рассказ составлен без наводящих вопросов, сюжет рассказа не повторяет рассказа педагога или других детей.

2. Целенаправленность. Отсутствие излишней детализации и перечислений.

3. Зачин, развитие сюжета, кульминация, концовка, умелое описание места действия, природы, портрета героя, его настроения.

Всё вышеперечисленное позволяет творческому рассказу иметь все признаки связного высказывания: логичность построения, связность частей - начало, середина, конец, наличие вводных слов для начала рассказа [7].

Таким образом, проанализировав психолого-педагогические исследования по проблеме детского речевого творчества можно сделать следующие выводы:

1. Детское речевое творчество - сложный процесс, относящийся к продуктивному виду деятельности. Эта деятельность обусловлена влиянием на ребёнка окружающего его мира и тем, какие впечатления от этого мира наиболее глубоко запомнились ребёнку, и выражается в создании ребёнком различных сочинений рассказов, сказок, стихов.

2. Самостоятельность при составлении связных законченных высказываний, смысловое соответствие творческих рассказов заявленной теме, чёткая выраженность структурных частей рассказа, отсутствие нарушений в построении предложений, полнота использования лексики - это показатели сформированности творческого рассказывания детей старшего дошкольного возраста.

Для изучения состояния связной речи детей дошкольного возраста существуют разные авторские методики.

Однако, задания, выявляющие уровень сформированности творческого рассказывания, отсутствуют.

В методике развития речи не существует строгой классификации творческих рассказов, но условно можно выделить следующие виды: рассказы реалистического характера; сказки; описания природы. Чаще всего дети создают тексты, которые содержат и описание, и действие, то есть описание сочетается с сюжетным действием.

Начинать обучение творческому рассказыванию лучше с придумывания рассказов реалистического характера. Приёмы обучения творческому рассказыванию зависят от умений детей, задач обучения и вида рассказа. Работу с детьми необходимо начинать с придумывания реалистических сюжетов. Наиболее лёгким принято считать придумывание продолжения и завершения рассказа. Начало рассказа должно заинтересовывать детей, знакомить с главным героем и его характером, с обстановкой, в которой происходит действие.

Анализ литературы по теме исследования показал, проблема развития умения рассказывать у старших дошкольников изучена в достаточной степени. Несмотря на это, остаётся не совсем разработанной одна из сто- 
рон этой проблемы - развитие умения рассказывать с использованием моделирования. А между тем моделирование является важнейшим приёмом, помогающим в овладении умением рассказывать. Как показывает практика, моделирование в дошкольном возрасте широко используется в развитии логического мышления. Системы работы по обучению умению рассказывать с использованием моделирования нет.

Моделирование - это попытка задействовать для решения познавательных задач зрительную, двигательную и ассоциативную память.

В основе моделирования лежит принцип замещения, то есть реальный предмет в деятельности детей замещается другим знаком, предметом или изображением.

На использовании наглядных моделей основаны многие методы дошкольного обучения. Это относится и к логопедии, где широко используют модели для обозначения слов, звуков в словах, предлогов.

Применительно к связной речи, модель - это схема явления, отражающая его структурные элементы и связи, наиболее существенные стороны и свойства объекта. В моделях связных высказываний речи это их структура, содержание: свойства объектов при описании, взаимоотношения героев и развитие событий в повествовании, средства внутритекстовой связи. Модели служат своеобразным зрительным планом для создания монологов, направляют процесс связного высказывания и помогают детям построить рассказ: его последовательность, наполнение и лексико-грамматическую структуру.

Как показывают данные исследований логопедов, психологов и педагогов, к началу школьного обучения уровень сформированности лексико-грамматических средств языка у детей с тяжёлыми нарушениями речи значительно отстаёт от нормы, самостоятельная связная монологическая речь у младших школьников долгое время остаётся несовершенной. Это создаёт детям дополнительные трудности в процессе обучения. В связи с этим формирование связной монологической речи старших дошкольников с тяжёлыми нарушениями речи приобретает первостепенное значение в общем комплексе коррекционных мероприятий.

У детей старшего дошкольного возраста, имеющих тяжёлые нарушения речи, формирование навыков творческого рассказывания представляет определённые трудности. Определение замысла рассказа, последовательное развитие выбранного сюжета, его языковая реализация - всё это вызывает затруднения у таких детей. Выполнение творческих заданий, например, составление небольшого рассказа на заданную тему, часто подменяется пересказом уже известного текста.

Нарушения связной речи чаще всего рассматривается как общая глобальная проблема при изучении разных видов речевого недоразвития.

В системе коррекционно-логопедической работы по формированию связной монологической речи дошкольников использование приёмов творческого рассказывания должно занимать особое место. Овладеть творческим рассказыванием - значит перейти на качественно новый уровень речемыслительной деятельности, то есть максимальное приближение речи ребёнка к такому состоянию связной монологической речи, которое необходимо ему для перехода к учебной деятельности.

Так как у дошкольников мыслительные операции решаются с помощью внешних средств, весь нагляд- ный материал усваивается лучше вербального. Метод наглядного моделирования способствует тому, что ребёнок может зрительно представить такие абстрактные понятия, как звук, слово, предложение, текст.

Наглядные модели - это способ задействовать почти все виды памяти ребёнка дошкольного возраста (зрительная, двигательная, ассоциативная) для решения умственных задач, так как дошкольник, в отличие от школьника, не способен сделать заметки, записать что-то. Наглядные модели доступны для понимания детям дошкольного возраста.

Исходя из этого, можно сделать вывод, что использование наглядных моделей актуально в работе с детьми дошкольного возраста:

1. Использование наглядного моделирования помогает поддержать интерес ребёнка на протяжении всего занятия и способствует снижению утомляемости.

2. Наглядное моделирование облегчает и ускоряет процесс запоминания предъявляемого материала.

3. Работа с наглядными моделями учит ребёнка выделять существенные признаки материала.

Наглядное моделирование распространено в разных областях науки. Специальная педагогика и логопедия разрабатывают теоретические и практические методы и приёмы, способствующие успешному образованию и воспитанию лиц с недостатками в психическом или физическом развитии. Наглядное моделирование способно, в некоторой степени, облегчить этот процесс, так как:

- способствует развитию замысла будущего продукта;

- позволяет менять точку зрения на ситуации или объекты изучения;

- стимулирует к самостоятельному анализу ситуации или объекта.

Моделирование в процессе развития связной речи используется как средство планирования высказывания. Это является особо значимым в работе над всеми видами связной монологической речи - пересказе, составлении рассказов по картине или серии картин, описательном рассказе и, безусловно, в творческом рассказывании.

Изучение состояния творческого рассказывания детей дошкольного возраста с тяжёлыми нарушениями речи в рамках изучения связной речи проводилось с использованием следующих методов:

- исследование сформированности творческого рассказывания с помощью серии заданий;

- исследование умений детей применять наглядные модели.

При разработке методики исследования мы опирались на работу В.П. Глухова и использовали некоторые его задания [3, с. 26]. В целом первый блок методики констатирующего эксперимента состоял из шести заданий.

Задание №1. Окончание рассказа по данному началу. Его цель - выявить возможности детей заканчивать рассказ по данному началу.

Для анализа выполнения детьми предложенных заданий были составлены следующие критерии оценки: самостоятельность, смысловое соответствие, содержание, связность, грамматическое оформление высказываний, лексика. 
На основании данных обследования выделены уровни сформированности умений детей старшего дошкольного возраста:

высокий - 3 балла;

средний - 2 балла;

низкий - от 0 до 1 балла.

Задание №2. Составление начала рассказа по данному его окончанию, целью которого было выявить возможности детей составлять начало рассказа по данному его окончанию.

Задание №3. Придумывание рассказа на заданную тему. Цель - выявить навыки составления связного высказывания с использованием заданных слов.

Задание №4. Зашифровка слов-предметов.

Задание №5. Зашифровка слов-действий.

Задание №6. Зашифровка слов-признаков. Цель выявить возможности детей кодировать информацию с помощью наглядных моделей.

В исследовании приняло участие 24 ребёнка 6-7 лет, имеющих тяжёлые нарушения речи.

Все дети с тяжёлыми нарушениями речи показали низкий уровень навыка сос

тавления связных высказываний: допускали грубые ошибки в построении предложений, в некоторых случаях неадекватно использовали слова, содержание высказываний отличалось крайней бедностью, их высказывания отличались незаконченностью мысли, нарушением грамматических норм и логических связей между частями высказываний, проявлением побочных ассоциаций, заменой слов в предложении.

Дети с тяжёлыми нарушениями речи показали низкие результаты в кодировании информации с помощью наглядных моделей. Легче всего для данной категории детей удалось зашифровать слова существительные, труднее глаголы. Самыми трудными для зашифровки оказались прилагательные.

Работа по обучению дошкольников творческому рассказыванию с использованием наглядного моделирования проводилась в три этапа. Первый этап - подготовительный. Второй этап - обучение творческому рассказыванию. Третий этап - заключительный.

Первый, подготовительный этап был посвящён творческим заданиям, позволяющим детям научиться кодированию информации с помощью наглядных моделей. Работа велась в определённой последовательности.

1. Знакомство с наглядными моделями слов и кодирование информации с помощью наглядных моделей.

2. Наглядные модели предметов ближайшего окружения необходимо было сделать простыми в исполнении, но легко понятными для восприятия детьми с тяжёлыми нарушениями речи. Самый доступный способ изготовления таких моделей - их контурное обозначение. Был сделан выбор в пользу таких наглядных моделей, которые, в последующем, дети с тяжёлыми нарушениями речи могли бы легко воспроизвести.

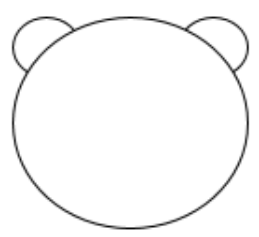

Рис. 1. Наглядная модель слова

Fig. 1. Appearance model of a word
3. Знакомство с диалогом. Составление диалогов по малосюжетным картинкам. Упражнения на разыгрывание диалогов.

Второй этап посвящён обучению творческому рассказыванию, включал в себя составление рассказов реалистического характера и был представлен следующими направлениями работы.

1. Придумывание продолжения и завершения рассказа, предложенного педагогом.

2. Придумывание начала рассказа, предложенного педагогом.

3. Составление рассказа по плану и моделям педагога.

Планы-схемы для составления рассказов реалистического характера представляли собой наборы наглядных моделей, манипулируя которыми и создавая из них различные комбинации, педагог мог бы в последующем использовать в работе с детьми. Такие наборы позволят развернуть рассказ на любую тему, заданную педагогом или выбранную детьми.

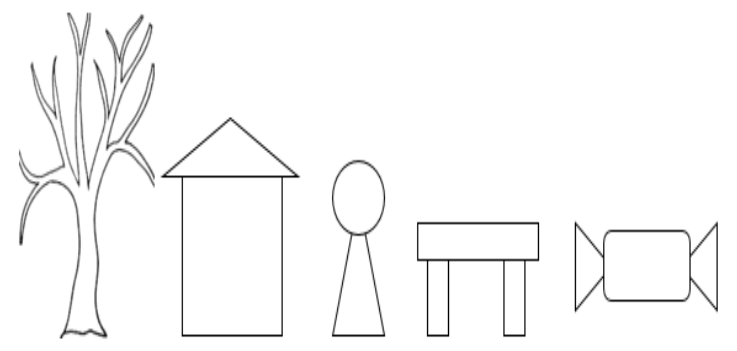

Рис. 2. Набор наглядных моделей для рассказа Fig. 2. Set of appearance models for a tale

4. Составление рассказа по плану и моделям, предложенными детьми.

Целью третьего, заключительного этапа было стимулирование детей к самостоятельному составлению рассказов творческого содержания с помощью метода наглядного моделирования.

Этот этап проходит в следующей последовательности.

1. Определение последовательности рассказа творческого содержания, составление плана данного вида рассказа, кодирование пунктов плана с помощью наглядных моделей.

2. Составление творческих рассказов сказочного содержания.

После проведения серии логопедических занятий с использованием наглядного моделирования по обучению творческому рассказыванию старших дошкольников с тяжёлыми нарушениями речи, был проведён контрольный срез с целью выявления динамики уровня сформированности умений. В контрольном срезе диагностировались 24 ребёнка с тяжёлыми нарушениями речи (12 детей контрольной группы и 12 детей экспериментальной группы). Анализ и обработка данных проводилась на основе использования тех же диагностических заданий, что и в начале исследования.

1. При выполнении заданий все дети экспериментальной группы проявили самостоятельность и не нуждались в помощи педагога. Дети контрольной группы выполняли задания со значительной помощью педагога.

2. При составлении рассказов творческого характера дошкольники экспериментальной группы старались раскрыть все смысловые звенья связного высказыва- 
ния, в то время как в контрольной группе проявлялась незаконченность мысли говорящего, смысловые звенья сокращались.

3. Содержание связных творческих высказывания детей экспериментальной группы отличалось разнообразием, с добавлением диалогов. В контрольной группе такого не отмечалось, содержание высказываний было беднее.

4. В экспериментальной группе пропуски важных в смысловом отношении слов и фраз не отмечались, в контрольной группе дети показали случаи отсутствия смысловой межфразовой связи.

5. У детей экспериментальной группы нарушения построения предложений были единичны. Между тем, в контрольной группе проявилось наличие аграмматизмов в предложениях.

6. Лексика детей экспериментальной группы достаточно разнообразна, словесной замены не наблюдалось. В контрольной группе дети проявляли словесные замены, происходил поиск слов.

7. При кодировании информации с помощью наглядных моделей в экспериментальной группе все дети самостоятельно выполнили задание и в подавляющем большинстве показали высокий уровень умений кодировать информацию с помощью наглядных моделей.
Между тем, половина детей контрольной группы не смогли выполнить данное задание.

Заключение. Разработанная система логопедических занятий и использование метода наглядного моделирования при составлении творческих рассказов на логопедических занятиях способствовали переходу процесса развития связной речи детей на более высокий уровень. Использование плана-схемы для облегчения логики построения связного высказывания, кодирование информации в наглядных моделях для облегчения запоминания слов всеми детьми, вариативность выбора слов-моделей для последующего творческого рассказа, участие всех детей в процессе создания наглядных моделей, запись текста в ходе составления творческого рассказа для последующего анализа речевой деятельности детей и создание миникнижек для демонстрации результата совместного труда доказало свою значимость в процессе обучения старших дошкольников с тяжёлыми нарушениями речи творческому рассказыванию с помощью метода наглядного моделирования.

Таким образом, достигнута цель, решены поставленные задачи и подтверждена гипотеза. Мы не претендуем на полноту разработки данной проблемы, считаем, что обучение творческому рассказыванию необходимо продолжать в следующем возрастном периоде.

\section{Список литературы}

1. Федеральный государственный образовательный стандарт дошкольного образования (утверждён приказом Министерства образования и науки Российской Федерации от 17 октября 2013 года №1155).

2. Выготский Л.С. Воображение и творчество в детском возрасте. Психологический очерк: книга для учителя. - 3-е изд. - М.: Просвещение, 1991. - 92 с.

3. Глухов В.П. Особенности формирования связной речи дошкольников с общим речевым недоразвитием. М.: Изд-во МГОПУ, 2001. - 194 с.

4. Глухов В.П. Наши дети учатся сочинять сказки / В.П. Глухов, Ю.А. Труханова. - М., 2005. - 24 с.

5. Короткова Э.П. Обучение детей дошкольного возраста рассказыванию. - М.: Просвещение, $1982 .-256$ с.

6. Обучение творческому рассказыванию детей 5-7 лет / авт.-сост. Л.М. Граб. - Волгоград: Учитель, 2010. - 136 с.

7. Семёнова И.В. Составление рассказов с элементами творчества // Воспитатель ДОУ. - 2009. - №7. - С. 79-84.

8. Танникова Е.Б. Формирование речевого творчества дошкольников. - М., 2008. - 95 с.

9. Навигатор образовательных программ дошкольного образования [Электронный ресурс]. - Режим доступа: http://www.firo.ranepa.ru/navigator-programm-do

\section{References}

1. Federal'nyi gosudarstvennyi obrazovatel'nyi standart doshkol'nogo obrazovaniia (utverzhdion prikazom Ministerstva obrazovaniia i nauki Rossiiskoi Federatsii ot 17 oktiabria 2013 goda №1155).

2. Vygotskii, L. S. (1991). Voobrazhenie i tvorchestvo v detskom vozraste. Psikhologicheskii ocherk., 92. M.: Prosveshchenie.

3. Glukhov, V. P. (2001). Osobennosti formirovaniia sviaznoi rechi doshkol'nikov s obshchim rechevym nedorazvitiem., 194. MGOPU.

4. Glukhov, V. P., \& Trukhanova, Iu. A. (2005). Nashi deti uchatsia sochiniat' skazki., 24. M.

5. Korotkova, E. P. (1982). Obuchenie detei doshkol'nogo vozrasta rasskazyvaniiu., 256. M.: Prosveshchenie.

6. Grab, L. M. (2010). Obuchenie tvorcheskomu rasskazyvaniiu detei 5-7 let., 136. Volgograd: Uchitel'.

7. Semionova, I. V. (2009). Sostavlenie rasskazov s elementami tvorchestva. Vospitatel' DOU, 7, 79-84.

8. Tannikova, E. B. (2008). Formirovanie rechevogo tvorchestva doshkol'nikov., 95. M.

9. Navigator obrazovatel'nykh programm doshkol'nogo obrazovaniia. Retrieved from http://www.firo.ranepa.ru/ navigator-programm-do

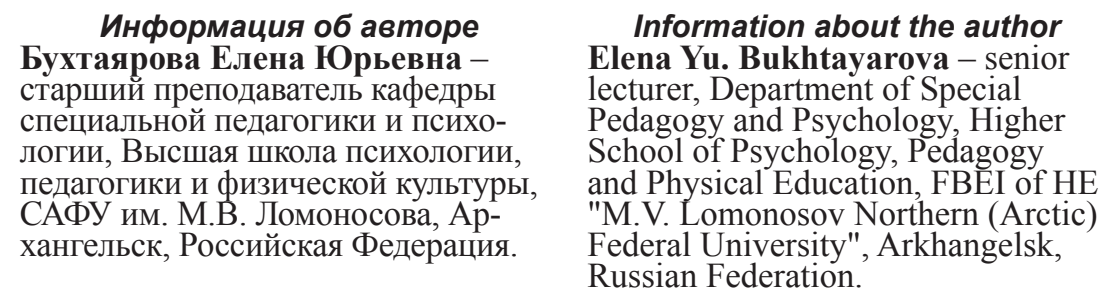

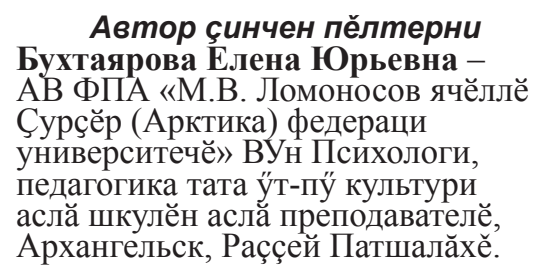

Автор съинчен пёлтерни
Бухтаярова Елена Юрьевна АВ ФПА «М.В. Ломоносов ячӗллӗ Сурс̧ӗр (Арктика) федераци университечё» ВУн Психологи, аслӑ шкулён аслӑ преподавателӗ, Архангельск, Рас̧с̧ей Патшалӑхе̌. 